\title{
Examination of the aerosol indirect effect under contrasting environments during the ACE-2 experiment
}

\author{
H. Guo ${ }^{1}$, J. E. Penner ${ }^{1}$, M. Herzog ${ }^{2}$, and H. Pawlowska ${ }^{3}$ \\ ${ }^{1}$ Department of Atmospheric, Oceanic and Space Sciences, University of Michigan, Ann Arbor, MI, USA \\ ${ }^{2}$ Geophysical Fluid Dynamics Laboratory, National Oceanic and Atmospheric Administration, Princeton, NJ, USA \\ ${ }^{3}$ Institute of Geophysics, Warsaw University, Warsaw, Poland
}

Received: 19 October 2006 - Published in Atmos. Chem. Phys. Discuss.: 20 November 2006

Revised: 19 January 2007 - Accepted: 19 January 2007 - Published: 29 January 2007

\begin{abstract}
The Active Tracer High-resolution Atmospheric Model (ATHAM) has been adopted to examine the aerosol indirect effect in contrasting clean and polluted cloudy boundary layers during the Second Aerosol Characterization Experiment (ACE-2). Model results are in good agreement with available in-situ observations, which provides confidence in the results of ATHAM.
\end{abstract}

Sensitivity tests have been conducted to examine the response of the cloud fraction (CF), cloud liquid water path (LWP), and cloud optical depth (COD) to changes in aerosols in the clean and polluted cases. It is shown for two cases that CF and LWP would decrease or remain nearly constant with an increase in aerosols, a result which shows that the second aerosol indirect effect is positive or negligibly small in these cases. Further investigation indicates that the background meteorological conditions play a critical role in the response of CF and LWP to aerosols. When large-scale subsidence is weak as in the clean case, the dry overlying air above the cloud is more efficiently entrained into the cloud, and in so doing, removes cloud water more efficiently, and results in lower CF and LWP when aerosol burden increases. However, when the large-scale subsidence is strong as in the polluted case, the growth of the cloud top is suppressed and the entrainment drying makes no significant difference when aerosol burden increases. Therefore, the CF and LWP remain nearly constant.

In both the clean and polluted cases, the COD tends to increase with aerosols, and the total aerosol indirect effect (AIE) is negative even when the CF and LWP decrease with an increase in aerosols. Therefore, the first AIE dominates the response of the cloud to aerosols.

\footnotetext{
Correspondence to: $\mathrm{H}$. Guo

(hguo@umich.edu)
}

\section{Introduction}

Clouds and their related physical processes represent one of the most complicated and perplexing problems in the study of climate change and weather forecasting (Stephens, 2005). One important cloud-related process is the interaction between aerosols, clouds, and radiation which determines the so-called aerosol indirect effect (AIE). Recent estimates of the AIE from global climate models (GCMs) were summarized by Lohmann and Feichter (2005). The first AIE (i.e., the effect of aerosols on the initial cloud drop size distribution) varies from -0.5 to $-1.9 \mathrm{Wm}^{-2}$, and the second AIE (i.e., the effect of aerosols on cloud precipitation efficiency, cloud lifetime, and cloud morphology) ranges from -0.3 to $-1.4 \mathrm{Wm}^{-2}$ at the top-of-the-atmosphere (Note: the negative sign indicates a cooling effect). If taken at face value, the largest of these estimates would imply that the magnitude of the AIE is larger than estimates of the total forcing from greenhouse gases plus natural causes of about $+2.7 \mathrm{Wm}^{-2}$ (IPCC 2001; Boucher and Haywood, 2001). However, a total negative (natural plus greenhouse gases plus aerosols) forcing would not be consistent with the observed changes of temperature (Knutti et al., 2002; Anderson et al., 2003). So this might indicate these estimates are too large.

Growing evidence for the difficulty in simulating aerosol effects in GCMs also stems from the application of large eddy simulation (LES) models and/or cloud resolving models (CRMs) to particular cloud systems (Jiang et al., 2002; Ackerman et al., 2004; Lu and Seinfeld, 2005; Jiang and Feingold, 2006) and to comparisons of the modeled response of CRMs and the modeled response of single column models (SCMs) to changes in aerosols (Johnson, 2005; Ovtchinnikov and Ghan, 2005). Direct comparison of CRMs and SCMs also shows that the latter often lack the refined resolution and physical interactions required to properly simulate the interactions between aerosols, clouds, and radiation (Ghan et al., 2000; Xu et al., 2002; Xie et al., 2002, 2005).

Published by Copernicus GmbH on behalf of the European Geosciences Union. 
Therefore, in this study, we apply a CRM, ATHAM (Active Tracer High-resolution Atmospheric Model) (Oberhuber et al., 1998; Herzog et al., 1998, 2003; Textor et al., 2003; Guo et al., $2007^{1}$ ), to explore the response of clouds to aerosols, i.e., the AIE.

It is well known that the attenuation of solar radiation by clouds is highly dependent on the cloud liquid water path (LWP) (Hansen and Travis, 1974; Stephens, 1978). Han et al. (1998) found that changes in the cloud optical depth (COD) were dominated by changes in the cloud LWP, rather than by changes in cloud droplet number concentration $\left(N_{d}\right)$ for optically thin clouds $(\mathrm{COD}<15)$. The LWP in clouds is highly dependent on the meteorological conditions that lead to the formation of the cloud, because the cloud liquid water content (LWC) is affected by various processes including cloud dynamics (updraft velocity, turbulence) and thermodynamics (Rogers and Yau, 1989). Jiang et al. (2002) pointed out that a weaker subsidence could increase the cloud LWP. Ackerman et al. (2004) emphasized that the response of the cloud LWP to changes in aerosols was determined by the competition between moistening from the suppression of precipitation and drying from the entrainment of overlying air. Only if the air above cloud layer was moist enough or the surface precipitation was significant enough, did the cloud LWP increase with aerosol loading. Otherwise, the cloud LWP could decrease with aerosol loading. Lu and Seinfeld (2005) showed that the cloud LWP was highly sensitive to the large-scale subsidence and sea surface temperature (SST). Therefore, the relationship between cloud LWP and aerosols is complicated by the conditions that influence the cloud LWP. Under different meteorological conditions, cloud LWP may either increase or decrease with increases in aerosols, and thereby either magnify or reduce the total AIE.

In addition to cloud LWP, cloud fraction is another critical factor determining the cloud radiative forcing. Chen and Penner (2005) pointed out that cloud fraction (CF) is the second largest uncertainty after aerosol burden for estimating aerosol forcing. However, the representation of $\mathrm{CF}$ is still elusive in weather and climate models; and changes in CF caused by aerosols have not been carefully evaluated. Recently measurement-based assessments showed that CF increased with non-absorbing aerosols (Kaufman et al., 2005; Kaufman and Koren, 2006). However, Lohmann et al. (2006) performed ECHAM4 GCM simulations, used a similar statistical analysis as that in Kaufman et al. (2005), and showed that $\mathrm{CF}$ and aerosol concentrations were positively correlated even without any aerosol indirect effect. Thus, in these simulations, the increase in CF was determined by the dynamics rather than the AIE. Penner et al. (2006) also studied the re-

\footnotetext{
${ }^{1}$ Guo, H., Penner, J. E., Herzog, M., and Xie, S.: Investigation of the first and second aerosol indirect effects on clouds during the May 2003 ARM Intensive Operational Period at Southern Great Plains, in review, 2007.
}

sponse of CF to changes in aerosols in $3 \mathrm{GCMs}$ and showed that the computed response was not statistically significant.

Large-eddy simulation results have demonstrated that CF can increase with increasing aerosol burden (Ackerman et al., 2003). However, Xue and Feingold (2006) presented contradictory or opposite results. They ascribed this decrease of $\mathrm{CF}$ with increasing aerosol burden to the ease of evaporation of the smaller cloud droplets that formed in this case. Therefore, it is important to investigate these effects further. The meteorological conditions, in addition to aerosols, also determine the radiative properties of clouds, and even dominate them. In order to "quantify" the assessment of the AIE, we should and must link the AIE with the meteorological conditions.

To advance our knowledge of the AIE, the first step is to understand the aerosol effect on a regional scale. The second Aerosol Characterization Experiment (ACE-2), was promoted by the International Global Atmospheric Chemistry project (Raes et al., 2000); and was carried out from 16 June to 24 July 1997 between Portugal, the Azores, and the Canary Islands $(29.4 \mathrm{~N}, 16.7 \mathrm{~W})$. The CLOUDY-COLUMN (CC) experiment, one of the six field projects during ACE-2, aimed to examine aerosol effects on the microphysical and radiative properties of marine boundary layer clouds (Brenguier et al., 2000a, 2003). Previous observations showed that the clean marine air over this area often alternates with the anthropogenic pollution originating from Europe and North Africa, and this alternation was also observed during ACE2 (Verver et al., 2000). Conditions during this alternation allowed us to examine aerosols, cloud properties, and their related processes in contrasting clean and polluted environments. This $\mathrm{CC}$ experiment also provided extensive, concomitant, and independent measurements of aerosols and clouds, which provided a good opportunity to explore the AIE for both experimentalists and modelers (Pawlowska and Brenguier, 2000, 2003; Menon et al., 2003).

The purpose of this study is to explore the impact of aerosols and meteorological conditions on the response of the cloud LWP, CF, and COD to changes in aerosols. The following questions will be addressed: (1) how do cloud LWP and CF respond to changes in aerosols? (2) How do large-scale meteorological conditions influence the response of cloud LWP and CF to aerosols, and how large is this influence?

The paper is organized as follows: Sect. 2 describes the clean and polluted base cases, and the simulation set-up. Section 3 discusses the model results from these base cases, and compares them with available observations. Section 4 presents sensitivity tests of the effects of changes in aerosols and the meteorological setting on the COD and radiative forcing. Section 5 summarizes our results. 

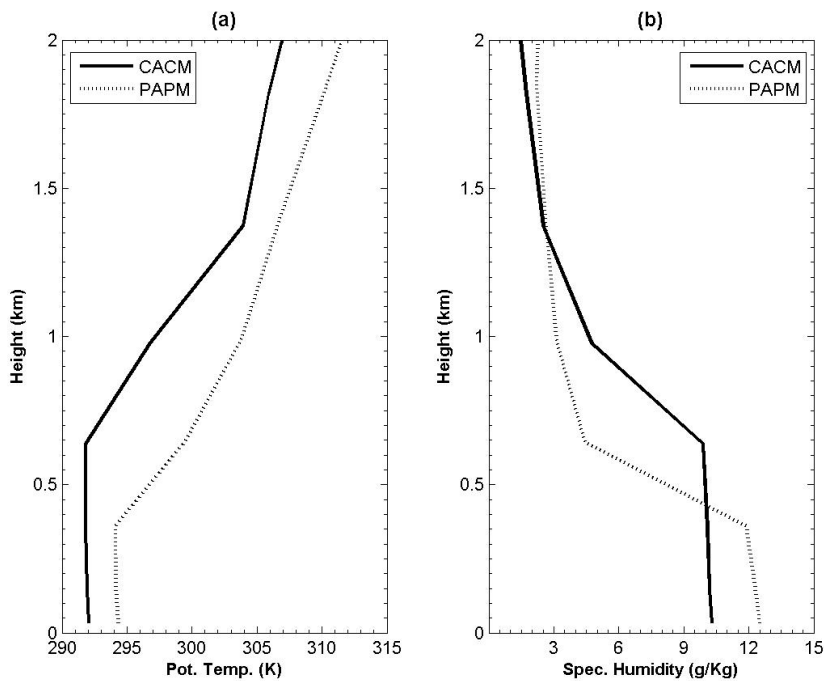

Fig. 1. Vertical profiles of the initial conditions: (a) potential temperature and (b) specific humidity for the clean base case on 26 June ("CACM") and for the polluted base case on 9 July ("PAPM").

\section{Case descriptions and simulation set-up}

\subsection{Case descriptions}

In this study, we focus on two contrasting marine stratocumulus cloud cases during the CC experiment. The first case is a pristine case on 26 June 1997, while the second is a polluted case on 9 July 1997 . The non sea-salt (nss) sulfate mass concentrations measured at the surface site at Punta del Hidalgo (PDH, $55 \mathrm{~m}$ a.s.1.) were $0.30 \pm 0.05 \mu \mathrm{g} \mathrm{m}^{-3}$ and $3.3 \pm 0.40 \mu \mathrm{g} \mathrm{m}^{-3}$ for average background conditions and for pollution outbreaks, respectively (Putaud et al., 2000). In this study we used $0.30 \mu \mathrm{g} \mathrm{m}^{-3}$ and $2.8 \mu \mathrm{g} \mathrm{m}^{-3}$ on 26 June and on 9 July, respectively (Guibert et al., 2003). At the Izana Observatory (IZO, $2370 \mathrm{~m}$ a.s.1.), the measured free troposphere nss-sulfate mass concentrations were $0.14 \pm 0.01$ and $0.61 \pm 0.03 \mu \mathrm{g} \mathrm{m}^{-3}$ for average background conditions and for pollution outbreaks, respectively (Putaud et al., 2000). (Note: measurements at IZO were available during the night time only (20:00-08:00 UTC), because during the daytime surface thermal winds brought the polluted low-altitude air up to IZO.)

The airborne condensation nuclei $(\mathrm{CN})$ counter measurement of the total aerosol number concentration was $218 \mathrm{~cm}^{-3}$ and $636 \mathrm{~cm}^{-3}$ on 26 June and on 9 July, respectively (Snider et al., 2000). Guibert et al. (2003) showed that the $\mathrm{CN}$ measurements from different aircraft (below and within cloud layers) and from the surface site were generally in good agreement with a difference of $<10 \%$ for both the clean and polluted cases. Aerosol mass mixing ratio was assumed to be constant with altitude below cloud base because the boundary layer was well mixed (Fig. 1) (Delene and Deshler, 2001; Penner et al., 2004), which was also con-
Table 1. Descriptions of two clean and polluted base cases ("CACM" and "PAPM"), and two sensitivity tests ("PACM" and "CAPM").

\begin{tabular}{lll}
\hline Tests & Aerosol loading & Meteorological setting \\
\hline "CACM" & Clean (26 June) & Clean (26 June) \\
"PACM" & Polluted (9 July) & Clean (26 June) \\
"CAPM" & Clean (26 June) & Polluted (9 July) \\
"PAPM" & Polluted (9 July) & Polluted (9 July) \\
\hline
\end{tabular}

firmed by the observations on 26 June and 9 July (Guibert et al., 2003). The aerosol concentrations above the boundary layer for both the clean ( 26 June) and polluted ( 9 July) cases from the M-IV airborne measurement were $\sim 400 \mathrm{~cm}^{-3}$ or $400 \mathrm{mg}^{-1}$ (Guibert et al., 2003).

These measured sulfate concentrations and total aerosol number concentrations were used in the parameterization of droplet nucleation which was based on Chuang and Penner (1995), where aerosol size distribution is determined by the condensation of sulfuric acid vapor $\left(\mathrm{H}_{2} \mathrm{SO}_{4}\right)$ on a prescribed pre-existing particle distribution and by aqueous-phase oxidation of $\mathrm{SO}_{2}$ followed by the evaporation of cloud drops. The prescribed pre-existing particles for the marine cases followed a three-mode log-normal distribution with mean diameters at $0.03,0.15$, and $0.5 \mu \mathrm{m}$, which was close to the observations of aerosol size distributions with diameters at 0.05 , 0.16 , and $0.5 \mu \mathrm{m}$ for the clean and polluted cases (Snider et al., 2003). For our implementation of this parameterization, we assumed that $75 \%$ of the mass fraction of sulfate (nsssulfate) was produced by the aqueous phase pathway, and resided on pre-existing accumulation mode particles, which followed a specified three-mode size distribution (Chuang and Penner 1995; Chuang et al., 1997). Hereafter, we denoted the clean base case (on 26 June) as "CACM" for "clean aerosol clean meteorology" and the polluted base case (on 9 July) as "PAPM" for "polluted aerosol polluted meteorology". Two sensitivity tests were also conducted, which were denoted as "PACM" and "CAPM" and are discussed in detail in Sect. 4 (see Table 1).

The alternation between clean and polluted cases (over the ACE-2 area) was governed by the location of the Azores High. Between 25 June and 3 July, Western Europe was under the influence of a cyclone, and this cyclone brought pristine marine polar air into the ACE-2 area. However, between 4 and 10 July, Western Europe was under the influence of the extension of the Azores High; and this high pressure brought about an outflow of anthropogenic pollution from Europe into the ACE-2 area (Verver et al., 2000). Between the "CACM" and the "PAPM", both the aerosol burden and the background meteorological conditions changed as a result of these two events. 

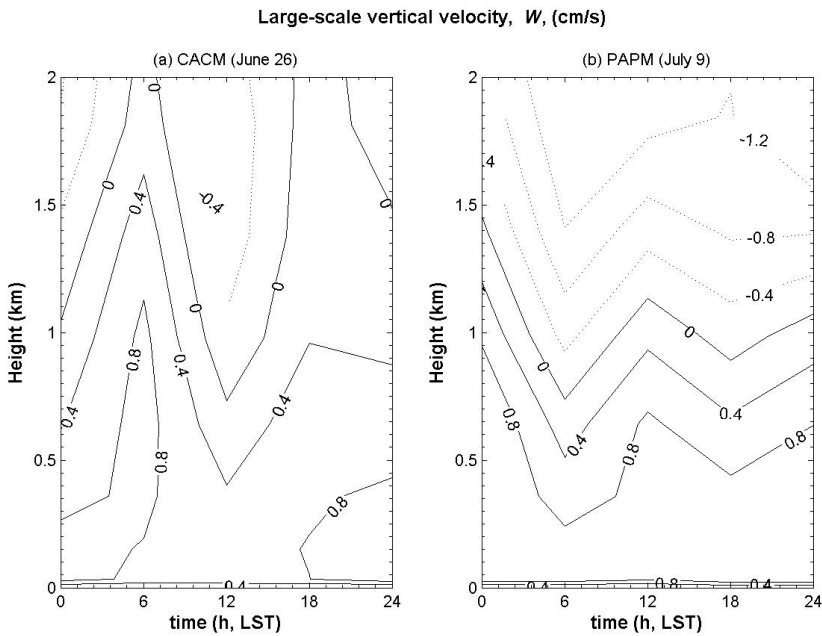

Fig. 2. Large-scale vertical velocity (W) from the ECMWF reanalysis data for the clean base case on 26 June ("CACM") and for the polluted base case on 9 July ("PAPM"). Contour intervals are $0.4 \mathrm{~cm} / \mathrm{s}$. (Note: solid lines are non-negative values, and dotted lines are negative values).

\subsection{Simulation set-up}

In this study, the three-dimensional version of ATHAM was applied (Oberhuber et al., 1998; Herzog et al., 1998, 2003; Textor et al., 2003; Guo et al., 2007 ${ }^{1}$ ). The horizontal domain used $64 \times 64$ grid points with a uniform spacing of $100 \mathrm{~m}$. The vertical spacing was uniformly $30 \mathrm{~m}$ below $2 \mathrm{~km}$ and then stretched to $300 \mathrm{~m}$ near the model top. We used a time step of $2 \mathrm{~s}$, and model results were archived every $5 \mathrm{~min}$.

ATHAM was initialized with the reanalysis data from European Centre for Medium-Range Weather Forecasts (ECMWF) (Fig. 1). In the "CACM" case, initially the boundary layer was capped by a strong inversion layer. Within the boundary layer, both the potential temperature and the specific humidity were almost constant with height (about $292 \mathrm{~K}$ and $10 \mathrm{~g} / \mathrm{kg}$ ). Above the inversion layer, the air was relatively dry (relative humidity 25\%). In the "PAPM" case, initially the boundary layer exhibited similar features to those in the "CACM", but it was shallower, warmer, and moister. This shallow boundary layer was due to the large-scale subsidence that is associated with the influence of the Azores High during the "PAPM" period. We assumed cloud free conditions at the beginning of all simulations.

The time- and height-dependent horizontal large-scale advection of temperature $(\mathrm{T})$ and moisture $(\mathrm{Q})$ were prescribed from the ECMWF reanalysis data. The corresponding vertical large-scale advection was calculated from the vertical gradients of the simulated $\mathrm{T}$ and $\mathrm{Q}$ profiles and the prescribed large-scale vertical velocity $(W)$ as shown in Fig. 2. It is evident that there is a weak large-scale subsidence in the "CACM" case but a very strong large-scale subsidence (up to $-1.2 \mathrm{~cm} / \mathrm{s}$ ) in the "PAPM" case between 1 and $2 \mathrm{~km}$, which is consistent with the dominance of the Azores High over the ACE2 area in the "PAPM" case. The modeled horizontally averaged wind components $(\mathrm{U}, \mathrm{V})$ from ATHAM were nudged towards the ECMWF re-analysis data with a relaxation time scale of $1 \mathrm{~h}$ (Grabowski et al., 1996). The ECMWF reanalysis data were available every six hours, so they were linearly interpolated to the temporal (and vertical) resolution of the ATHAM grids between these times.

Our model simulations began at 18:00 LST (local standard time) and the entire simulation period was $30 \mathrm{~h}$. The first 6-h of the simulations were regarded as a spinup and our analysis was only performed for the last 24-h.

\section{Base case results}

In the base case study, we compared the model results with available observations in order to examine the extent to which our model is able to reproduce observations. The most extensive observations were conducted close to local noon (Brenguier et al., 2000a, 2000b; Snider et al., 2000; Snider et al., 2003). The flight time, on 26 June was from 11:50 LST to 14:50 LST, while on 9 July, it was from 12:40 LST to 15:50 LST, and, our comparisons were conducted at the corresponding flight time.

\subsection{Cloud vertical profiles}

Figures 3 and 4 show the simulated and observed vertical profiles of cloud liquid water content (LWC), cloud droplet number concentration $\left(N_{d}\right)$, and cloud droplet mean volume diameter $\left(d_{v}\right)$ within cloud layers for the "CACM" and "PAPM" cases, respectively. The LWC increases with the height above cloud base $(\sim 1.2 \mathrm{~km}$ for the "CACM" case and $\sim 0.8 \mathrm{~km}$ for the "PAPM" case, respectively); $N_{d}$ remains almost constant within cloud layers; and $d_{v}$ increases with height above cloud base as expected if $N_{d}$ is constant.

The comparison of LWC with the adiabatic LWC is illustrated in Figs. 3-4a and d. The difference between the modeled LWC and the adiabatic LWC becomes larger with height above cloud base due to the mixing of dry air from above the cloud, especially in the "PAPM" case.

In both the "CACM" and "PAPM" cases, the simulated $N_{d}$ is slightly higher than the observed $N_{d}$ near cloud base (Figs. 3-4b and e), which is partly due to the fact that the lower size limit of the Fast-FSSP (Forward Scattering Spectrometer Probe) measurement is $1.3 \mu \mathrm{m}$ in radius (Brenguier et al., 2003). $N_{d}$ decreases at cloud top $(\sim 1.45 \mathrm{~km}$ for the "CACM" case and $\sim 0.95 \mathrm{~km}$ for the "PAPM' case, respectively), due to the entrainment of dry air from above the cloud. We also note that the difference between $d_{v}$ and the adiabatic $d_{v}$ (solid lines in Figs. 3-4c and f) is small from cloud base to cloud top in both the ATHAM results and airborne measurements. This might suggest that the mixing between cloudy air and dry air above clouds tends to 

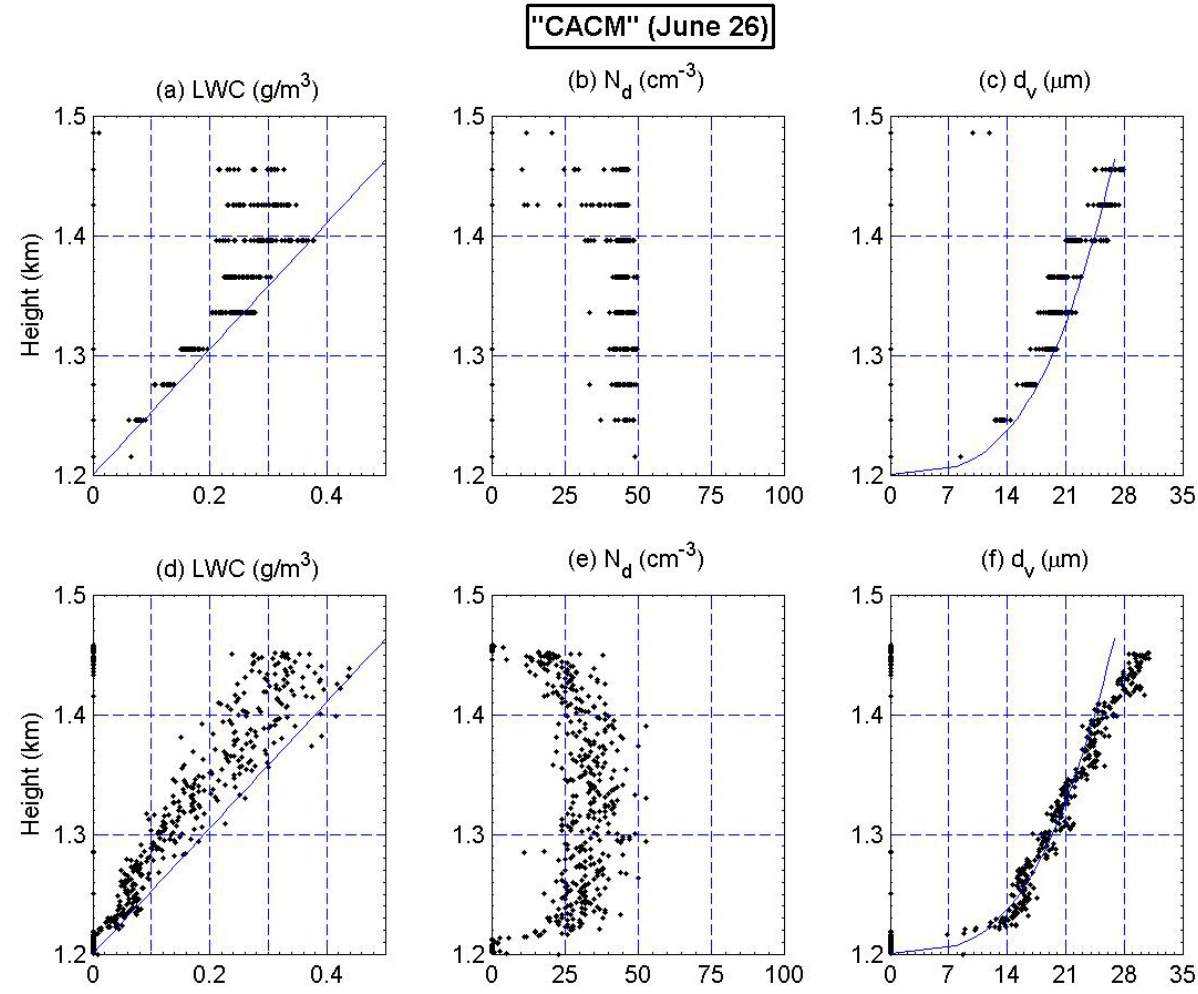

Fig. 3. Vertical profiles of the cloud microphysical properties for the "CACM" case on 26 June from the model (ATHAM) results (a-c) and from airborne measurements (d-f) sampled in the cloudy region around local noon: cloud liquid water content (LWC) is shown in (a) and (d), cloud droplet number concentration $\left(N_{d}\right)$ in (b) and (e), and droplet volume mean diameter $\left(d_{v}\right)$ in (c) and (f). The solid lines in (a) and (d) refer to the adiabatic LWC; and the solid lines in (c) and (f) refer to the adiabatic $d_{v}$, assuming $N_{d}=50 \mathrm{~cm}^{-3}$ for the "CACM" case.

be heterogeneous because $N_{d}$ becomes smaller but $d_{v}$ remains close to the adiabatic $d_{v}$ at cloud top. However, this convergence of $d_{v}$ towards the adiabatic $d_{v}$ is less evident in ATHAM than in the measurements. This might be because ATHAM treats mixing as homogeneous rather than heterogeneous (Guo et al., 2007 ${ }^{1}$ ), a problem that many CRMs or large eddy simulation models share (Grabowski et al., 2006). The standard deviation of the simulated $d_{v}$ is about $2 \sim 5 \mu \mathrm{m}$, which is larger than that of the observed $d_{v}(2 \sim 3 \mu \mathrm{m})$ (Pawlowska et al., 2006). This might be partly due to the different sampling strategies used in the model and measurements. We sampled over all cloudy cells within the numerical domain, while the observations sampled over the traverse of the aircraft through a cloud.

3.2 Vertical velocity and cloud droplet number concentration spectra

As noted above, the mechanistic aerosol activation scheme of Chuang and Penner (1995) was adopted, in which the initial $N_{d}$ predicted at cloud base depends on the updraft velocity $w$. Figure 5 compares probability density functions (PDFs) of $w$ near cloud base from ATHAM and from the airborne measurements for the "CACM" case and for the "PAPM" case. The solid lines represent modeled PDFs of $w$ and the dashed lines represent the measurements around local noon. The modeled $w$ captures the peaks and the spread of the frequency distribution of the observed $w$ very well. The simulated mean values $(\bar{w})$ and the standard deviations $\left(\sigma_{w}\right)$ agree reasonably well with the observed values (difference $<30 \%$ ) for both the "CACM" and the "PAPM" cases. $\bar{w}$ is less than the measurement bias of $0.3 \mathrm{~m} / \mathrm{s}$ (Brown, 1993; Guibert et al., 2003), but $\sigma_{w}$ is relatively large, especially in the "PAPM" case. Therefore, the average of the vertical velocity is close to zero within the boundary layer; and local fluctuations due to boundary layer turbulence are a major contributor to the updraft at cloud base. This turbulence, therefore, leads to the activation of aerosols, as well as the vertical transport of moisture, mass, and energy.

$N_{d}$ is calculated from a budget equation (Lohmann et al., 1999), which takes advective transport, turbulent transport, and microphysical sinks and sources into account as follows:

$$
\begin{aligned}
\frac{\partial N_{d}}{\partial t}= & R\left(N_{d}\right)+Q_{\text {nucl }}-Q_{\text {auto }}\left(N_{d}\right)-Q_{\text {self }} \\
& -\frac{N_{d}}{\mathrm{LWC}}\left(Q_{\text {accr }}+Q_{\text {evap }}\right),
\end{aligned}
$$

where $R\left(N_{d}\right)$ refers to the advective and turbulent transport of $N_{d}$, and $Q_{\text {nucl }}, Q_{\text {auto }}\left(N_{d}\right)$, and $Q_{\text {self }}$ refer to the rates 

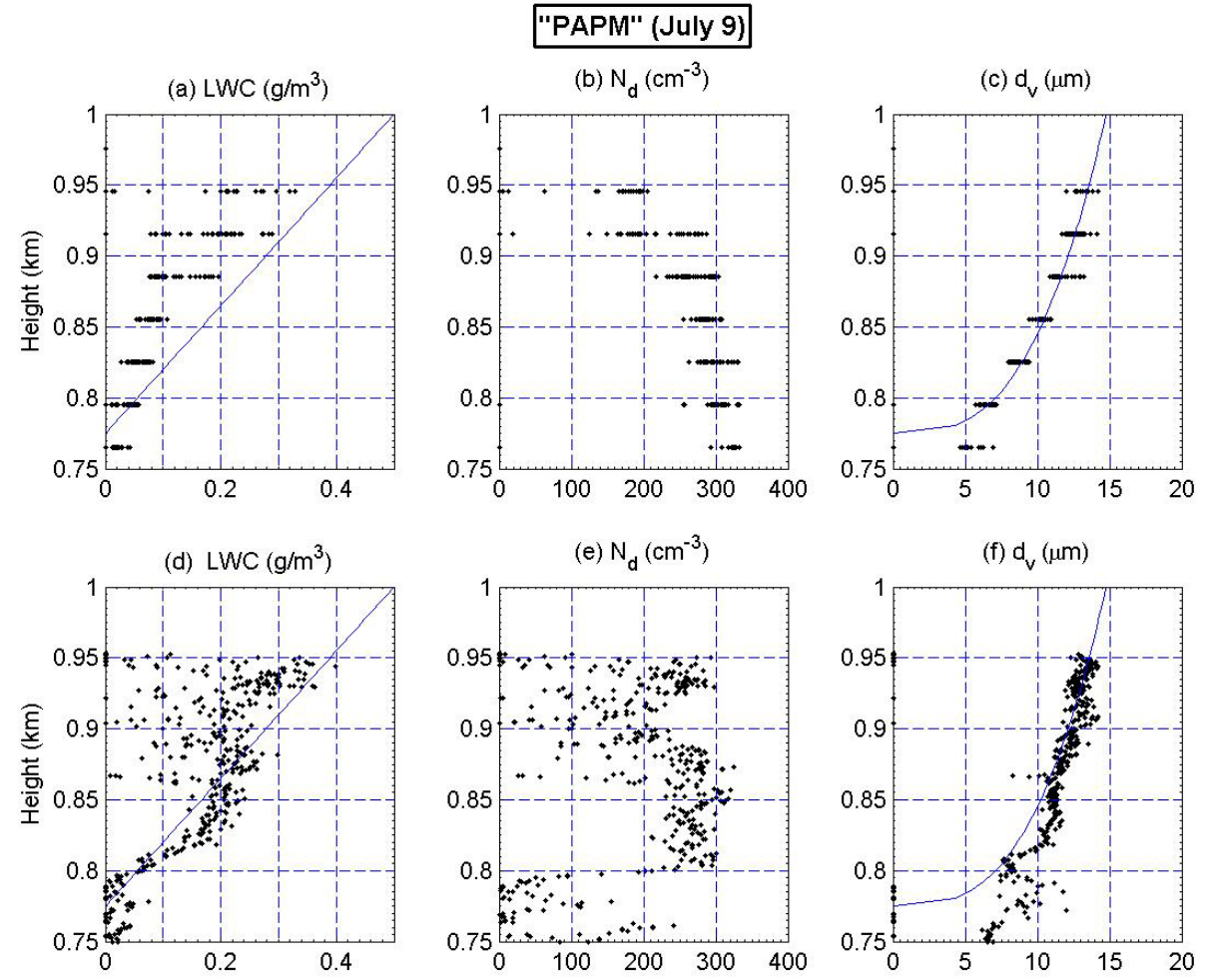

Fig. 4. Same as in Fig. 3 but for the "PAPM" case. The solid lines in (c) and (f) refer to the adiabatic $d_{v}$, assuming $N_{d}=300 \mathrm{~cm}^{-3}$ for the "PAPM" case.

for nucleation, autoconversion, and self-collection of cloud droplets, respectively. $Q_{\text {accr }}$ and $Q_{\text {evap }}$ refer to the rates of accretion and evaporation, respectively.

Figure 6 presents cloud droplet number concentration spectra at five evenly-spaced cloud layers with $N_{d}>20 \mathrm{~cm}^{-3}$ from ATHAM and from the airborne measurements for the "CACM" case at the heights of $1.25,1.29,1.33,1.37$, and $1.41 \mathrm{~km}$, respectively. The sample selection criterion of $N_{d}>20 \mathrm{~cm}^{-3}$ is to achieve a statistically significant estimate of $d_{v}$ and LWC derived from the Fast-FSSP measurements (Brenguier et al., 2003). At cloud base, the simulated droplet number concentration spectra agree well with the observed spectra. This is expected because the updraft velocity $w$ compares favorably with the observed $w$ and the aerosol chemical composition and number concentrations used in ATHAM are from observations. However, near cloud top, the agreement between the simulated and the observed spectra is not as good as that at cloud base, although the mean value $\left(\overline{N_{d}}\right)$ and the associated standard deviation $\left(\sigma_{N_{d}}\right)$ are still close to the observed values (difference $<10 \%$ ). These differences might be caused by the lack of representation of heterogeneous sub-grid scale mixing as mentioned in Sect. 3.1. For the polluted "PAPM" case, the results of the comparison between modeled and observed number concentration spectra are similar to those for the "CACM" case, and therefore, are not shown here.

\subsection{Other cloud properties}

Figures 7 and 8 show the time series of CF, in-cloud LWP, domain average LWP, $N_{d}, d_{v}$, and COD. It is clear that the model results are generally well within the uncertainties of the observations. For example, the averaged in-cloud LWPs from ATHAM are $\sim 19.6 \mathrm{~g} \mathrm{~m}^{-2}$ and $\sim 13.5 \mathrm{~g} \mathrm{~m}^{-2}$ for the "CACM" and for the "PAPM" cases, respectively, which are well within the observations $\left(18.5 \pm 17.8 \mathrm{~g} \mathrm{~m}^{-2}\right.$ and $11.0 \pm 10.8 \mathrm{~g} \mathrm{~m}^{-2}$, respectively) (Menon et al., 2003). We also note that the in-cloud LWP for the "PAPM" case is smaller than that for the "CACM" case, which would not be expected if caused by the second AIE. The reason is that the polluted cloud system in the "PAPM" case tends to be shallower and drier (as shown in Figs. 3-4) largely due to its continental origin (Verver et al., 2000; Pawlowska and Brenguier, 2003).

$\mathrm{CF}$ is defined as the fraction of model cloudy columns, and a cloudy column is a column containing cloudy grid cells with liquid water mixing ratio $>0.01 \mathrm{~g} / \mathrm{kg}$ and $N_{d}>5 \mathrm{~cm}^{-3}$ (Pawlowska and Brenguier, 2003). The observed CFs are from a Compact Airborne Spectrographic Imager (CASI) (indicated as " $x$ " in Figs. 7-8a) and from the International Satellite Cloud Climatology Project (ISCCP) (indicated as "o") (Schroder et al., 2002; Menon et al., 2003). In both the "CACM" and the "PACM" cases, the simulated CFs are 
(a) Probability density function ( $\mathrm{s} / \mathrm{m}$ ) of $w$ in the "CACM" case (June 26)

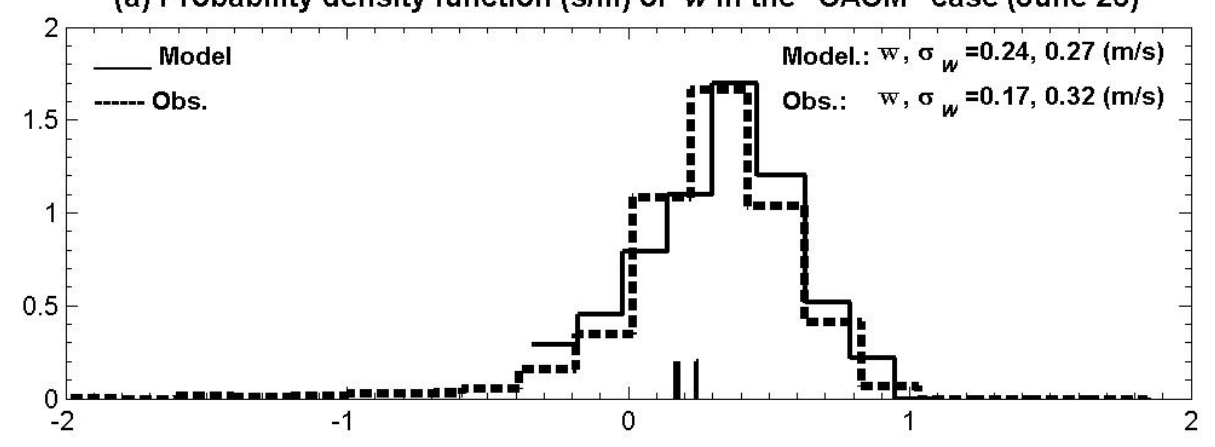

(b) Probability density function ( $\mathrm{s} / \mathrm{m}$ ) of $w$ in the "PAPM" case (July 9)

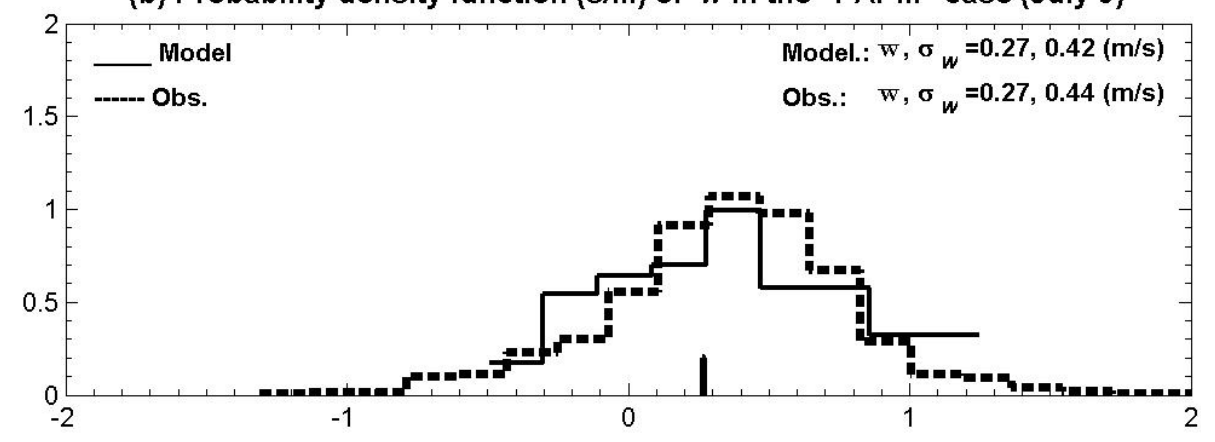

Fig. 5. Probability density function of the vertical velocity $(w)$ near cloud base from the model (ATHAM) results (solid) and from airborne measurements (dashed) in the "CACM" case in (a) and in the "PAPM" case in (b). The vertical bars on the X-axis represent the mean values $(\bar{w})$.

overestimated, especially at night and in the early morning. This discrepancy might be due to three reasons: (1) the sample area: the ATHAM domain $\left(6.4 \times 6.4 \mathrm{~km}^{2}\right)$ is much smaller than that of ISCCP $(250 \mathrm{~km})$; (2) the cloud scene identification criterion in the retrieval of $\mathrm{CF}$ is too strict: for example, in both the "CACM" and the "PAPM" cases, CFs are $\sim 90 \%$ from the airborne sampling, but they are $<80 \%$ from the CASI retrieval (Brenguier et al., 2003); (3) the existence of shallow and broken clouds, which are difficult to retrieve (Menon et al., 2003).

\section{Sensitivity tests}

Here we consider sensitivity studies to examine how the CF and cloud LWP respond to changes in the aerosol burden, and how the meteorological conditions might amplify/reduce this response. Two sensitivity tests were performed to isolate the effect of aerosols and the effect of the meteorological conditions on cloud properties (Table 1). For these tests, the aerosol burdens between the "CACM" and the "PAPM" cases were swapped. We denoted the test which combined the aerosol loading in the "PAPM" case with the meteorological setting in the "CACM" case as the "PACM". The case where the aerosol burden from the "CACM" case was used with the meteorological setting in the "PAPM" case was de- noted "CAPM". As in the base cases, these two sensitivity tests were run for $36 \mathrm{~h}$, and we analyzed the results of the last $24 \mathrm{~h}$.

\subsection{Response of CF and LWP to changes in aerosol burden}

\subsubsection{Clean meteorology case}

As discussed in the introduction, the CF and LWP are important for determining the cloud radiative forcing. In both the "CACM" and the "PACM" cases, CFs and LWPs have a significant diurnal variation: $C F s$ reach their maxima $(\sim 100 \%$ and $\sim 95 \%$, respectively) during the local early morning and their minima ( $\sim 75 \%$ and $\sim 45 \%$, respectively) in the local afternoon; the in-cloud LWPs reach $65.9 \mathrm{~g} \mathrm{~m}^{-2}$ and $48.7 \mathrm{~g} \mathrm{~m}^{-2}$ in the morning, and $14.8 \mathrm{~g} \mathrm{~m}^{-2}$ and $10.5 \mathrm{~g} \mathrm{~m}^{-2}$ in the afternoon. However, both the CF and LWP are generally larger in the "CACM" case than in the "PACM" case. At local noon when the solar radiation is strong, the $\mathrm{CF}$ in the "CACM" case is about twice that in the "PACM" case and the in-cloud LWP in the "CACM" case about $40 \%$ larger (Fig. 7). The daily average $\mathrm{CF}$ in the "CACM" case is larger than that in the "PACM" by $12 \%$ and the daily average in-cloud LWP in the 'CACM' case is about 27\% larger (Table 2).

Ackerman et al. (2004) pointed out that the cloud water content is affected not only by precipitation, but also by the 


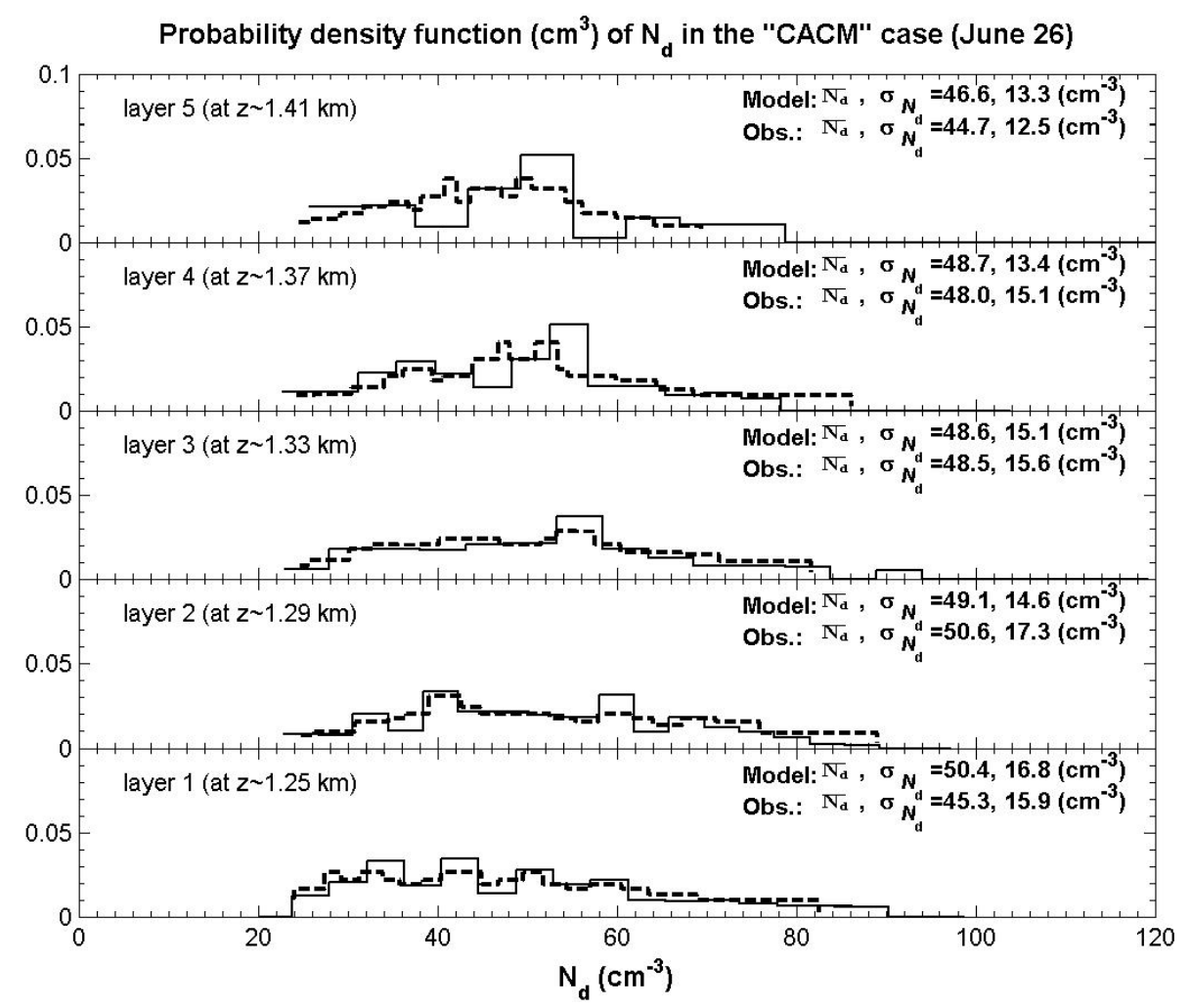

Fig. 6. Probability density function for the droplet number concentration $\left(N_{d}\right)$ at five evenly-spaced cloud layers with $N_{d}>20 \mathrm{~cm}^{-3}$ from the model (ATHAM) (solid) and from airborne measurements (dashed) in the "CACM" case.

Table 2. Daily-mean and standard deviation of cloud fraction (CF), in-cloud liquid water path (LWP), cloud droplet number concentration $\left(N_{d}\right)$, droplet volume mean diameter $\left(d_{v}\right)$, and cloud optical depth (COD) for the four cases.

\begin{tabular}{cccccccccccc}
\hline Cases & \multicolumn{2}{c}{$\begin{array}{c}\text { CF } \\
(\%)\end{array}$} & \multicolumn{2}{c}{$\begin{array}{c}\text { In-cloud LWP } \\
\left(\mathrm{g} \mathrm{m}^{-2}\right)\end{array}$} & \multicolumn{2}{c}{$\begin{array}{c}N_{d} \\
\left(\mathrm{~cm}^{-3}\right)\end{array}$} & \multicolumn{2}{c}{$\begin{array}{c}d_{v} \\
(\mu \mathrm{m})\end{array}$} & & COD \\
& mean & Std. & mean & Std. & mean & Std. & mean & Std. & mean & Std. \\
\hline "CACM" & 91.93 & 6.66 & 33.89 & 15.22 & 41.51 & 3.95 & 16.90 & 2.40 & 4.95 & 1.57 \\
"PACM" & 79.19 & 15.07 & 26.72 & 13.98 & 236.18 & 14.16 & 9.27 & 1.00 & 7.24 & 3.01 \\
"CAPM" & 73.18 & 7.91 & 14.62 & 2.15 & 47.59 & 2.82 & 13.92 & 0.70 & 2.62 & 0.31 \\
"PAPM" & 72.80 & 6.66 & 14.94 & 2.76 & 248.33 & 24.26 & 8.85 & 0.65 & 4.44 & 0.59 \\
\hline
\end{tabular}

entrainment of dry air from above clouds. Since surface precipitation is small $(<0.05 \mathrm{~mm} /$ day $)$ in both the "CACM" and in the "PACM" cases, the response of cloud water to aerosols is primarily determined by the entrainment of dry air at cloud top.

Figure 9a presents the time series of the averaged cloud top height. It is clear that the cloud top growth rate is smaller in the "CACM" case $(0.71 \mathrm{~cm} / \mathrm{s})$ than in the "PACM" case $(0.75 \mathrm{~cm} / \mathrm{s})$. Since the entrainment rate can be approximated by the difference between the cloud top growth rate and the large-scale vertical velocity (Moeng et al., 1999; Jiang et al., 2002; Stevens et al., 2003a, b), and since the large-scale vertical velocity (subsidence) is the same in the "CACM" and in the "PACM" cases, the entrainment rate is smaller in the "CACM" case than that in the "PACM" case. This is consistent with large eddy simulation results (Jiang et al., 2002; Ackerman et al., 2004). For the clean case, the net latent heat release associated with precipitation formation (which allows increased condensation) offsets the radiative cooling near the cloud top, which lessens the negative buoyancy and vertical motions (particularly in the downdrafts) of air parcels (Fig. 9c), thereby decreasing the kinetic energy (Fig. 9b) and reducing the entrainment (Fig. 9a). Moreover, the air above clouds is relatively dry with a relative humidity (RH) of $\sim 25 \%$ (Fig. 10). Therefore, the drying by entrainment in the "CACM" case is not as efficient as that in the "PACM" 
(a) $\mathrm{CF}(\%)$

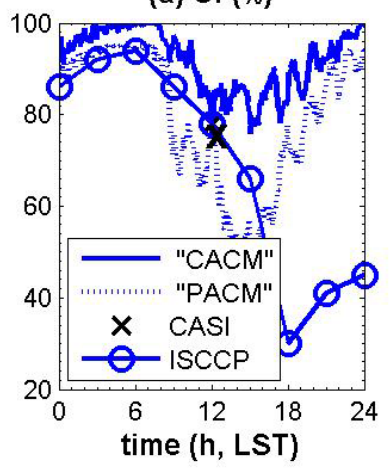

(d) $\mathrm{N}_{\mathrm{d}}\left(\mathrm{cm}^{-3}\right)$

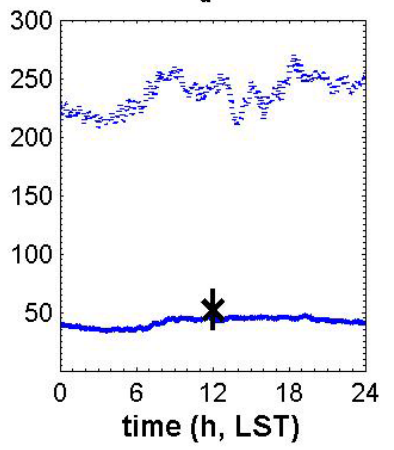

(b) in-cloud LWP $\left(\mathrm{g} \mathrm{m}^{-2}\right)$

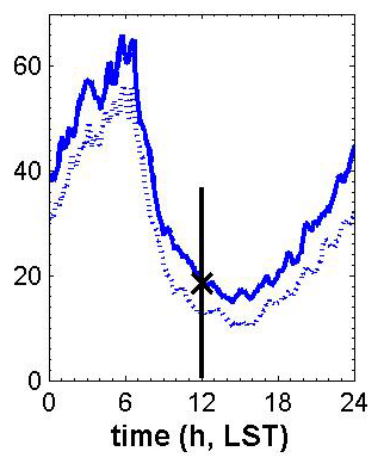

(e) $d_{v}(\mu \mathrm{m})$

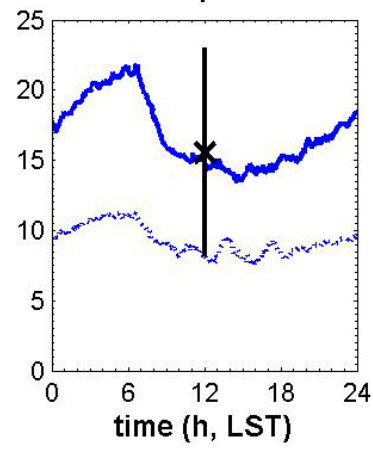

(c) domain LWP $\left(\mathrm{g} \mathrm{m}^{-2}\right)$

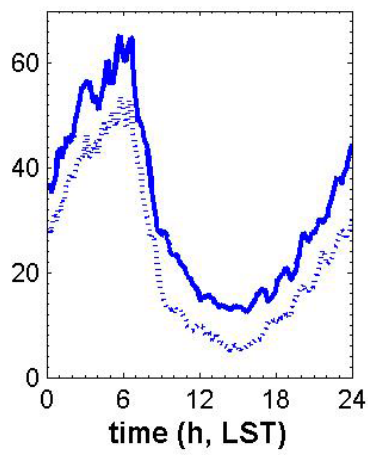

(f) $C O D$

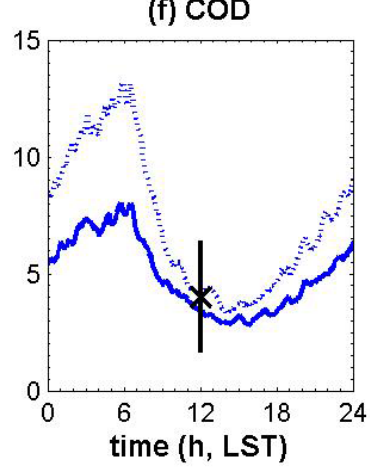

Fig. 7. Time series of cloud fraction (a), in-cloud liquid water path (LWP) (b), domain-average LWP (c), droplet number concentration $N_{d}$ (d), droplet volume mean diameter $d_{v}$ (e), and cloud optical depth (COD) (f) for the "CACM" case (solid) and for the "PACM" case (dotted). Observed values and their uncertainties are also indicated with " $x$ " and vertical bars.

case, and the clouds are moister and CF and LWP are larger in the "CACM" case.

We also note that the largest difference in the CF between the "CACM" case and the "PACM" case occurs at local noon when the $\mathrm{CF}$ reaches a minima. This might be due to the dependence of the entrainment rate on the inverse of the cloud radius (Blyth et al., 1988). The decreased CF in the "PACM" case, or the smaller cloud radius, allows cloudy air to have a larger surface area to mix with the drier ambient air, and thus enhances the entrainment. This in turn reduces the cloud radius (and the cloud moisture) further.

\subsubsection{Polluted meteorology case}

CFs and LWPs are similar in the "CAPM" and in the "PAPM" cases (Fig. 8). The differences in their daily averages are well within their standard deviations (Table 2). There is negligible surface precipitation and the air above clouds is even drier than that in the "CACM" and "PACM" cases $(\mathrm{RH}<20 \%)$ (Fig. 10), but the cloud top growth is highly suppressed by the strong large-scale subsidence on 9 July (Figs. 2 and 11a). This strong subsidence warming dominates the net latent heating associated with precipitation formation in the cloud; and masks the difference between the vigor of the vertical motions, TKE, and entrainment between the "CAPM" and the "PAPM" cases (Figs. 11). As a result, there is almost no difference in the cloud top growth rates in the "CAPM" case $(0.47 \mathrm{~cm} / \mathrm{s})$ and in the "PAPM" case, which means that the difference in the entrainment drying is negligible, so that this does not give rise to a noticeable difference in cloud water. Consequently, cloud water contents are similar in the "CAPM" and in the "PAPM", and so are CFs and LWPs.

\subsection{Response of COD to changes in aerosol burdens}

Although the response of the CF and LWP to aerosols is negative or neutral (as discussed in Sect. 4.1), the response of the COD to increases in aerosol burden tends to be positive (Figs. 7-8). As expected from the 1st AIE (Twomey et al., 1977), $N_{d}$ increases and $d_{v}$ decreases when aerosol burdens increase (Figs. 7-8). Since the broad band COD can be approximated by $\frac{3 \mathrm{LWP}}{\beta d_{v} \rho_{w}}$, where $\rho_{w}$ is the liquid water density $\left(1000 \mathrm{~kg} \mathrm{~m}^{-3}\right)$, and $\beta$ is a parameter that measures the ratio between the droplet effective radius and the droplet volume mean radius (droplet effective radius is defined as the ratio of the third to the second moment of the droplet size distribution). $\quad \beta$ is $\sim 1.08$ for maritime clouds (Martin et al., 1994). Therefore, a decrease of COD with increases in aerosol burden would only occur if the decrease 
(a) $\mathrm{CF}(\%)$

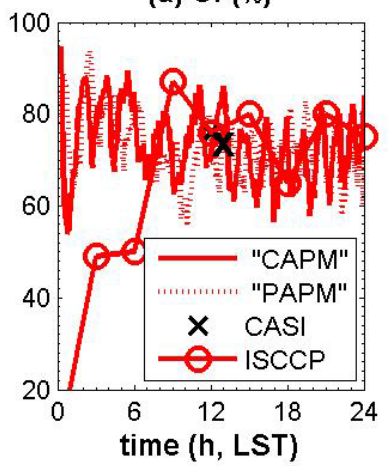

(d) $\mathrm{N}_{\mathrm{d}}\left(\mathrm{cm}^{-3}\right)$

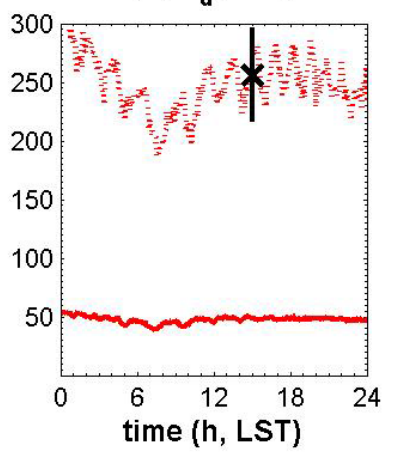

(b) in-cloud LWP(g m $\left.{ }^{-2}\right)$

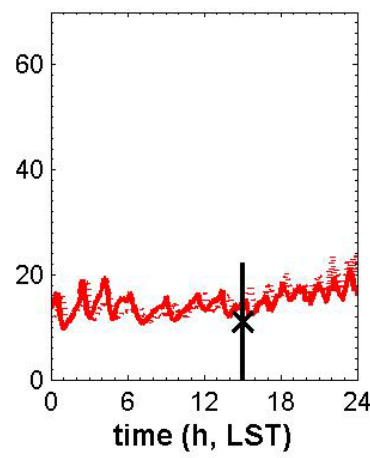

(e) $d_{v}(\mu \mathrm{m})$

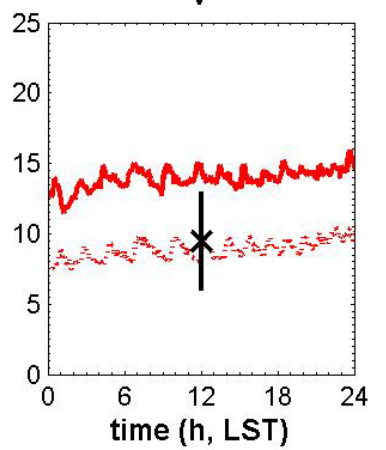

(c) domain LWP $\left(\mathrm{g} \mathrm{m}^{-2}\right)$

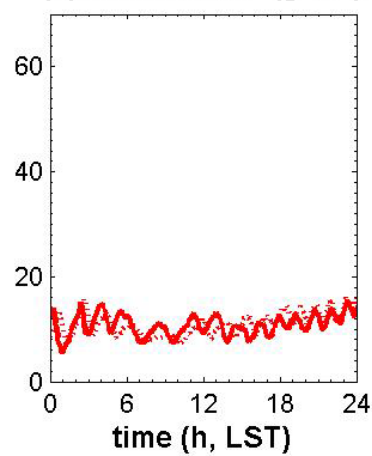

(f) $C O D$

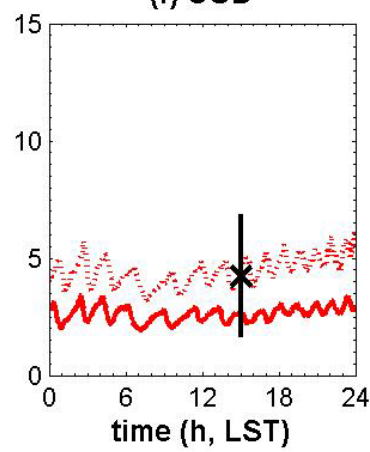

Fig. 8. Same as in Fig. 7 but for the "CAPM" case (solid) and for the "PAPM" case (dotted).

(a) cloud top height $(\mathrm{km})$

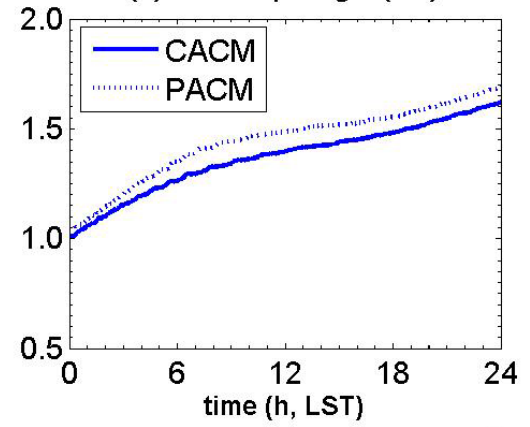

(b) vertically integrated TKE $\left(\mathrm{Kg} / \mathrm{s}^{2}\right)$

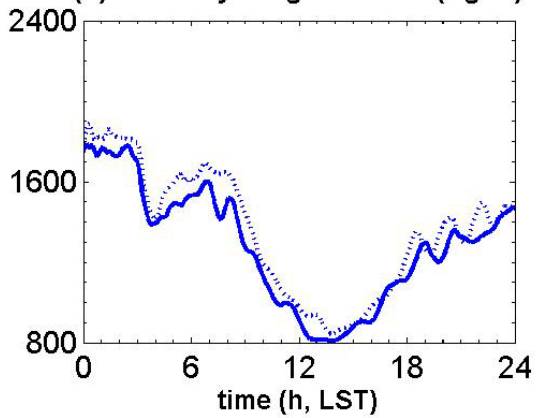

(c) $\overline{\mathrm{ww}}\left(\mathrm{m}^{2} / \mathrm{s}^{2}\right)$

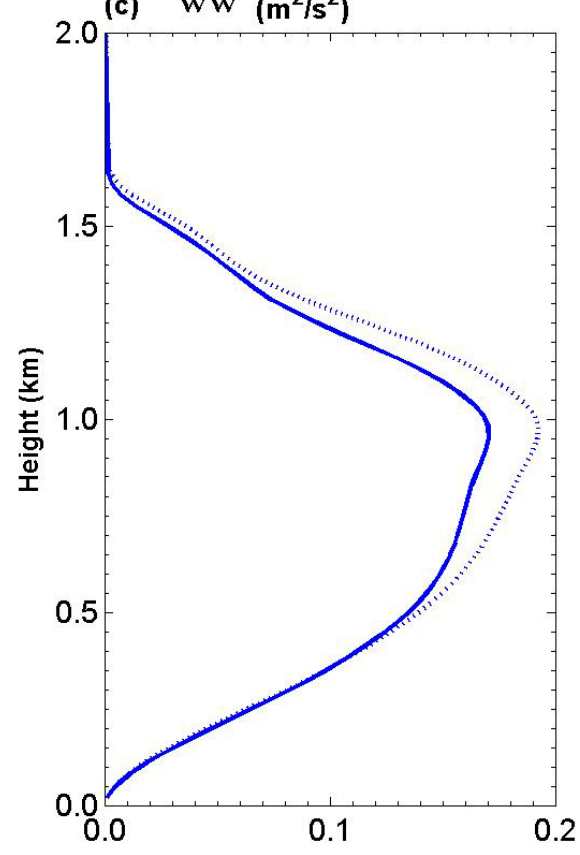

Fig. 9. Time series for the "CACM" case (solid) and for the "PACM" (dotted) case: of the (a) horizontally-averaged height of the cloud tops $(\mathrm{km})$, and (b) vertically integrated turbulent kinetic energy (TKE) under $2 \mathrm{~km}\left(\mathrm{~kg} / \mathrm{s}^{2}\right)$; (c) is the time average over the last $24 \mathrm{~h}$ of the profiles of $w$ variance $\overline{w w}\left(\mathrm{~m}^{2} / \mathrm{s}^{2}\right)$. 

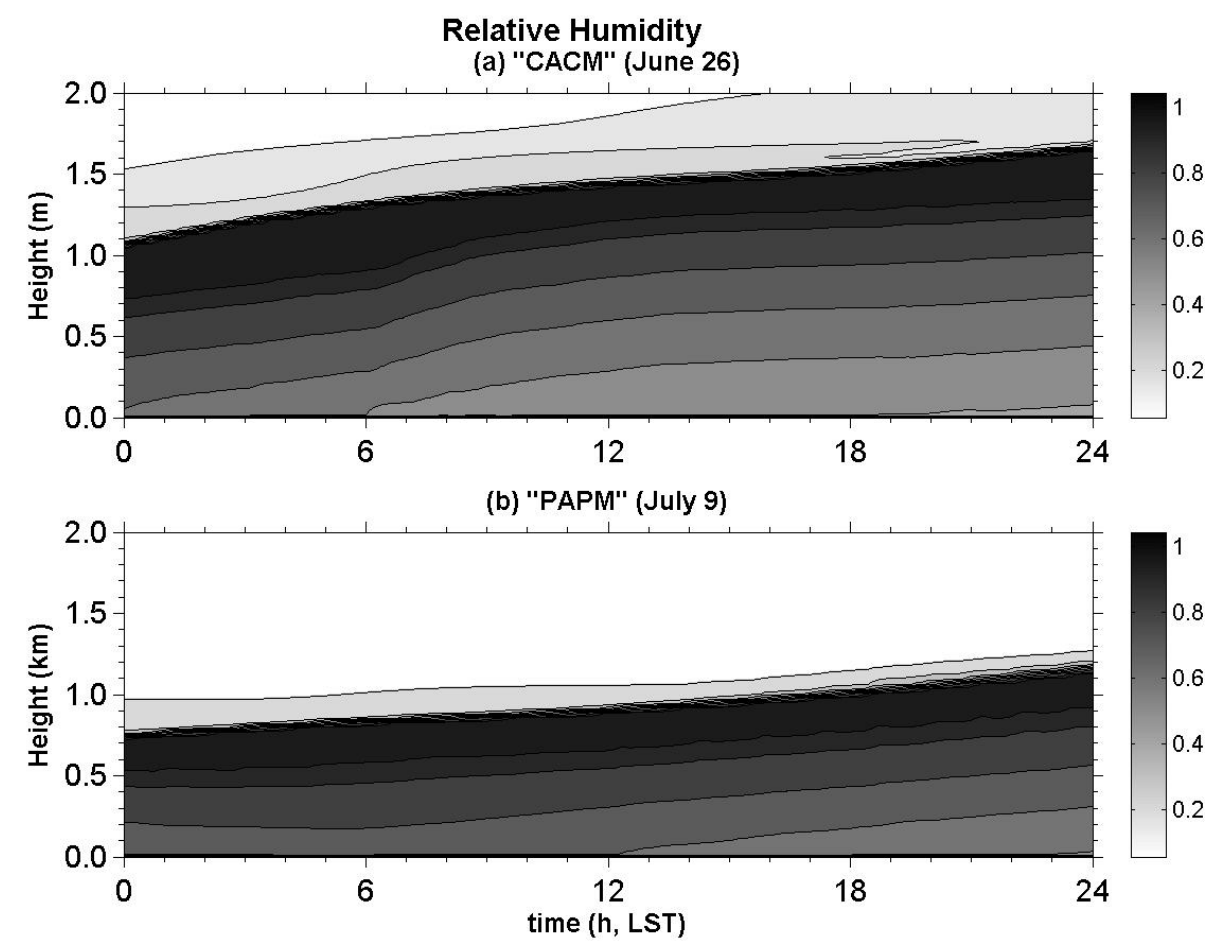

Fig. 10. Time-height cross section of the horizontally-averaged relative humidity (RH) for the "CACM" case (a) and for the "PAPM" case (b).

in the LWP with aerosols is faster than the decrease of $d_{v}$. Although a decrease of $d_{v}$ with an increase in aerosols is observed (Penner et al., 2004), the LWP can either increase or decrease with aerosols ( $\mathrm{Lu}$ and Seinfeld, 2005). In this study, the decrease of LWP is not as significant as the decrease of $d_{v}$ (Table 2). On the whole, the COD increases with increasing aerosol burden.

\subsection{Radiative forcing estimates}

Here, we evaluate radiative effects of changes in aerosol burden in the clean and polluted cases. $\Delta \mathrm{F}_{t}$ is the difference in the net incoming radiative flux $\left(\Delta \mathrm{F}_{\text {net }}\right)$, where the net incoming radiation is the sum of the shortwave plus longwave incoming radiation and downward is positive, either at the top-of-the-atmosphere (TOA) or at the surface between simulations with clean and polluted aerosol burden but with the same meteorological conditions, and is given by

$$
\Delta \mathrm{F}_{t} \text { (“CM”) }=\mathrm{F}_{\text {net }} \text { (“PACM") }-\mathrm{F}_{\text {net }} \text { (“CACM") }
$$

or

$$
\Delta \mathrm{F}_{t} \text { ("PM") }=\mathrm{F}_{\text {net }} \text { ("PAPM") }-\mathrm{F}_{\text {net }} \text { ("CAPM"). }
$$

Where $\Delta \mathrm{F}_{t}$ ("CM") is the total AIE with the meteorological setting of the clean base case on 26 June; and $\Delta \mathrm{F}_{t}$ ("PM") is the total AIE with the meteorological setting of the polluted base case on 9 July.
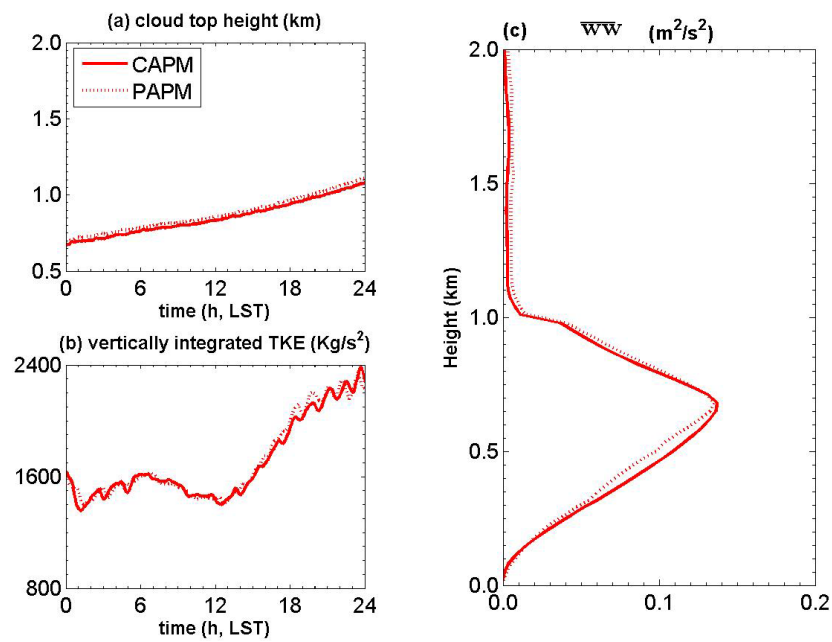

Fig. 11. Same as in Fig. 9 but for the "CAPM" case (solid) and for the "PAPM" case (dotted).

The first and second aerosol indirect effects are often entangled in the real atmosphere, so that there is no simple way to isolate them. Because the first AIE is induced by the increases in $N_{d}$ due to anthropogenic pollution (Twomey et al., 1977), and $N_{d}$ is more or less constant within cloud layers (Fig. 3), we replaced $N_{d}$ in the base cases with the averaged $N_{d}$ from the sensitivity tests, and estimated the first AIE 
Table 3. The daily and spatially averaged total aerosol indirect effect $\left(\Delta \mathrm{F}_{t}\right)$, first aerosol indirect effect $\left(\Delta \mathrm{F}_{1}\right)$, and second aerosol indirect effect $\left(\Delta \mathrm{F}_{2}\right)$ at the top-of-the-atmosphere and at the surface. These averages are derived from instantaneous calculations of every 5 min of model time. "CM" refers to the meteorological conditions for the clean base case on 26 June; and "PM" refers to the meteorological conditions for the polluted base case on 9 July.

\begin{tabular}{ccccccc}
\hline & \multicolumn{2}{c}{$\begin{array}{c}\text { top-of-the-atmosphere } \\
\left(\mathrm{W} \mathrm{m} \mathrm{m}^{-2}\right)\end{array}$} & \multicolumn{3}{c}{$\begin{array}{c}\text { surface } \\
\left(\mathrm{W} \mathrm{m} \mathrm{m}^{-2}\right)\end{array}$} \\
\hline & $\Delta \mathrm{F}_{t}$ & $\Delta \mathrm{F}_{1}$ & $\Delta \mathrm{F}_{2}$ & $\Delta \mathrm{F}_{t}$ & $\Delta \mathrm{F}_{1}$ & $\Delta \mathrm{F}_{2}$ \\
\hline "CM" & -8.8 & -19.5 & +10.7 & -10.6 & -20.9 & +10.3 \\
"PM" & -6.4 & -6.0 & -0.4 & -6.8 & -6.2 & -0.6 \\
\hline
\end{tabular}

offline $\left(\Delta \mathrm{F}_{1}\right)$. Thus, we calculated the $\Delta \mathrm{F}_{1}$ under the clean meteorological conditions for the clean base case on 26 June $\left(\Delta \mathrm{F}_{1}\right.$ ("CM")) and under the polluted meteorological conditions for the polluted base case on 9 July $\left(\Delta \mathrm{F}_{1}\right.$ ("PM")).

The second indirect effect $\left(\Delta \mathrm{F}_{2}\right)$ is estimated as the difference between $\Delta \mathrm{F}_{t}$ and $\Delta \mathrm{F}_{1} ;$ so $\Delta \mathrm{F}_{2}$ is given by

$$
\Delta \mathrm{F}_{2} \text { (“CM") }=\Delta \mathrm{F}_{t} \text { (“CM") }-\Delta \mathrm{F}_{1} \text { (“"CM") }
$$

or

$$
\Delta \mathrm{F}_{2} \text { (“PM") }=\Delta \mathrm{F}_{t} \text { (“PM") }-\Delta \mathrm{F}_{1} \text { (“PM"). }
$$

Table 3 summarizes the daily averaged $\Delta \mathrm{F}_{t}, \Delta \mathrm{F}_{1}$, and $\Delta \mathrm{F}_{2}$ using above method. The magnitude of $\Delta \mathrm{F}_{t}$ ("CM") is smaller than that of $\Delta \mathrm{F}_{1}$ ("CM"), and results in a positive $\Delta \mathrm{F}_{2}$ ("CM"). This is expected because both $\mathrm{CF}$ and LWP decreased with an increase in the aerosol burden in the "CACM" and "PACM" cases.

The magnitudes of $\Delta \mathrm{F}_{t}$ ("PM"), $\Delta \mathrm{F}_{1}$ ("PM"), and $\Delta \mathrm{F}_{2}$ ("PM") are smaller than those of $\Delta \mathrm{F}_{t}$ ("CM"), $\Delta \mathrm{F}_{1}$ ("CM"), and $\Delta \mathrm{F}_{2}$ ("CM") mainly because the clouds on 9 July are relatively drier and shallower. The magnitude of $\Delta \mathrm{F}_{t}$ ("PM") is similar to that of $\Delta \mathrm{F}_{1}$ ("PM"), and $\Delta \mathrm{F}_{2}$ ("PM") is close to $0 \mathrm{Wm}^{-2}$, which is consistent with the neutral responses of CF and LWP to increases in aerosols under the strong large-scale subsidence on 9 July.

\section{Conclusions and discussion}

A cloud resolving model has been used to study the aerosol indirect effect during the second Aerosol Characterization Experiment (ACE-2). The model is able to reproduce the cloud characteristics in both the clean and polluted base cases. The simulated cloud vertical profiles, updraft velocity near cloud base, and cloud droplet number concentration spectra are in good agreement with the observations.

The mean value of the updraft velocity near cloud base is generally small, but the standard deviation is large, which indicates that local fluctuations caused by turbulence, rather than the mean updraft, determine the aerosol activation process. Heterogeneous mixing between cloudy air and clear air near cloud top is not well simulated because the underlying assumption for the turbulence mixing scheme in ATHAM is homogeneous (Herzog et al., 2003).

Sensitivity tests were performed by swapping the aerosol burden and the meteorological conditions between the clean and polluted base cases in order to explore the response of the cloud fraction, cloud water path, and cloud optical depth to increases in aerosols. Our results show that neither the cloud fraction nor the cloud liquid water path necessarily increase with increases in aerosols. When there is a weak large-scale subsidence and dry overlying air above clouds, the stronger entrainment of dry air (due to a reduction of the net latent heating implied by the suppression of precipitation; and thus an enhancement of the cooling of air parcels and their negative buoyancy and kinetic energy) in the polluted aerosol scenario effectively dries the cloud, and gives rise to a lower cloud fraction and cloud liquid water path (i.e., a negative response). However, when the large-scale subsidence is strong and suppresses the rise of the cloud top, this entrainment drying does not result in a significant difference in cloud water for different aerosol burdens. The cloud fraction and cloud liquid water path are not sensitive to changes in the aerosol burden (i.e., neutral response).

The second aerosol indirect effect could either enhance or reduce the first aerosol indirect effect, depending on the large-scale subsidence. So different meteorological conditions could either magnify or diminish the first indirect effect. Because of these complications, evaluation of the second aerosol indirect effect is complex and challenging.

Nevertheless, the total aerosol indirect effect still tends to be negative, that is, it exerts a cooling effect. Even when the cloud fraction and liquid water path decrease with increases in aerosols, the cloud optical depth tends to be larger in the polluted aerosol scenario (due to the smaller cloud droplet size). For the clean meteorological case, we found a positive second aerosol indirect effect that decreased the total indirect effect, but did not change the sign of the total indirect effect.

Acknowledgements. This work was supported by the U.S. Department of Energy Atmospheric Radiation Measurement (ARM) Program under grant \#DEFG02-97-ER62370.

Edited by: U. Lohmann

\section{References}

Ackerman, A. S., Toon, O. B., Stevens, D. E., and Coakley Jr., J. A.: Enhancement of cloud cover and suppression of nocturnal drizzle in stratocumulus polluted by haze, Geophys. Res. Lett., 30(7), 1381, doi:10.1029/2002GL016634, 2003.

Ackerman, A. S., Kirkpatrick, M. P., Stevens, D. E., and Toon, O. B.: The impact of humidity above stratiform clouds on indirect aerosol climate forcing, Nature, 432, 1014-1017, 2004. 
Anderson, T. L., Charlson, R. J., Schwartz, S. E., Knutti, R., et al.: Climate forcing by aerosols - a hazy picture, Science, 300, 1103-1104, 2003.

Blyth, A. M., Cooper, W. A., and Jensen, J. B.: A study of the source of entrained air in Montana cumuli, J. Atmos. Sci., 45, 3944-3964, 1988.

Boucher, O. and Haywood, J.: On summing the components of radiative forcing of climate change, Clim. Dyn., 18(3-4), 297-302, 2001.

Brown, E. N.: Measurement uncertainties of the NCAR air motion system, NCAR Tech. Note., NCAR/TN-386+STR, 1993.

Brenguier, J.-L., Chuang, P. Y., Fouquart, Y., Johnson, D. W., et al.: An overview of the ACE-2 CLOUDYCOLUMN closure experiment, TELLUS, 52B, 815-827, 2000a.

Brenguier, J.-L., Pawlowska, H., Schuller, L., Preusker, R., Fischer, J., and Fouquart, Y.: Radiative properties of boundary layer clouds: droplet effective radius versus number concentration, J. Atmos. Sci., 57, 803-821, 2000b.

Brenguier, J.-L., Pawlowska, H., and Schuller, L.: Cloud microphysical and radiative properties for parameterization and satellite monitoring of the indirect effect of aerosol on climate, J. Geophys. Res., 108, 8632, doi:10.1029/2002JD002682, 2003.

Chen, Y. and Penner, J. E.: Uncertainty analysis for estimates of the first indirect aerosol effect, Atmos. Chem. Phys., 5, 2935-2948, 2005 ,

http://www.atmos-chem-phys.net/5/2935/2005/.

Chuang, C. and Penner, J.: Effect of anthropogenic sulfate on cloud drop nucleation and optical properties, Tellus, 47, 566577, 1995.

Chuang, C., Penner, J., Taylor, K. E., Grossman, A. S., and Walton, J. J.: An assessment of the radiative effects of anthropogenic sulfate, J. Geophys. Res., 102, 3761-3778, 1997.

Delene, D. J. and Deshler, T.: Vertical profiles of cloud condensation nuclei above Wyoming, J. Geophys. Res., 106, 12579 12 588, 2001.

Ghan, S., Randall, D., Xu, K.-M., Cederwall, R., et al.: A comparison of single column model simulations of summertime midlatitude continental convection, J. Geophys. Res., 105, 2091-2124, 2000 .

Grabowski, W. W., Wu, X., and Moncrieff, M. W.: Cloud resolving modeling of tropical systems during Phase III of GATE. PART I: Two-dimensional experiments, J. Atmos. Sci., 53, 3684-3709, 1996.

Grabowski, W. W.: Indirect impact of atmospheric aerosols in idealized simulations of convective-radiative quasi-equilibrium, J. Climate, 19, 4664-4682, 2006.

Guibert, S., Snider J. R., and Brenguier, J.-L.: Aerosol activation in marine stratocumulus clouds 1 . Measurement validation for a closure study, J. Geophys. Res., 108(D15), 8628, doi:10.1029/2002JD002678, 2003.

Han, Q., Rossow, W., Chou, J., and Welch, R.: Global survey of the relationships of cloud albedo and liquid water path with droplet size using ISCCP, J. Climate, 11, 1516-1528, 1998.

Hansen, J. E. and Travis, L. D.: Light scattering in planetary atmospheres, Space Sci. Rev., 16, 527-610, 1974.

Herzog, M., Graf, H., Textor, C., and Oberhuber, J. M.: The effect of phase changes of water on the development of volcanic plumes, J. Volcanol. Geotherm. Res., 87, 55-74, 1998.

Herzog, M., Oberhuber, J. M., and Graf, H. F.: A prognostic tur- bulence scheme for the non-hydrostatic plume model, J. Atmos. Sci., 60, 2783-2796, 2003.

IPCC, Intergovernmental Panel on Climate Change: Climate Change 2001, The Scientific Basis, Cambridge University Press, 2001.

Jiang, H., Feingold, G., and Cotton, W. R.: Simulations of aerosol-cloud-dynamical feedbacks resulting from entrainment of aerosol into the marine boundary layer during the Atlantic Stratocumulus Transition Experiment, J. Geophys. Res., 107(D24), 4813, doi:10.1029/2001JD001502, 2002.

Jiang, H. and Feingold, G.: The effect of aerosol on warm convective clouds: aerosol-cloud-surface flux feedbacks in a new coupled large eddy model, J. Geophys. Res., 111(D1), 202, doi:10.1029/2005JD006138, 2006.

Johnson, B. T.: The semidirect aerosol effect: Comparison of a single-column model with large eddy simulation for marine stratocumulus, J. Climate, 18(1), 119-130, 2005.

Kaufman, Y. J., Koren, I., Remer, L. A., Rosenfeld, D., and Rudich, Y.: The effect of smoke,dust, and pollution aerosol on shallow cloud development over the Atlantic Ocean, Proc. Natl. Acad. Sci., 102, $11207-11212,2005$.

Kaufman, Y. J. and Koren, I.: Smoke and pollution aerosol effect on cloud cover, Science, 313, 655-658, 2006.

Knutti, R., Stocker, T. F., Joos, F., and Plattner, G.-K.: Constraints on radiative forcing and future climate change from observations and climate model ensembles, Nature, 416, 719-723, 2002.

Lohmann, U., Feichter, J., Chuang, C. C., and Penner, J. E.: Prediction of the number of cloud droplets in the ECHAM GCM, J. Geophys. Res., 104(D8), 9169-9198, 1999.

Lohmann, U. and Feichter, J.: Global indirect aerosol effects: a review, Atmos. Chem. Phys., 5, 715-737, 2005, http://www.atmos-chem-phys.net/5/715/2005/.

Lohmann, U., Koren, I., and Kaufman, Y. J.: Disentangling the role of microphysics and dynamical effects in determining cloud properties over the Atlantic, Geophys. Res. Lett., 33, L09802, doi:10.1029/2005GL024625, 2006.

Lu, M.-L. and Seinfeld, J. H.: Study of the aerosol indirect effect by large-eddy simulation of marine stratocumulus, J. Atmos. Sci., 62, 3909-3932, 2005.

Martin, G. M., Johnson, D. W., and Spice, A.: The measurement and parameterization of effective radius of droplets in warm stratocumulus clouds, J. Atmos. Sci., 51(13), 1823-1842, 1994.

Moeng, C.-H., Sullivan, P. P., and Stevens, B.: Including radiative effects in an entrainment rate formula for buoyancy-driven PBLs, J. Atmos. Sci., 56, 1031-1049, 1999.

Menon, S., Brenguier, J.-L., Boucher, O., Davison, P., et al.: Evaluating aerosol/cloud/radiation process parameterizations with single-column models and Second Aerosol characterization Experiment (ACE-2) cloudy column observations, J. Geophys. Res., 108(D24), 4762, doi:10.1029/2003JD003902, 2003.

Oberhuber, J., Herzog, M., Graf, H., and Schwanke, K.: Volcanic plume simulation on large scales, J. Volcanol. Geotherm. Res., 87, 29-53, 1998.

Ovtchinnikov, M. and Ghan, S. J.: Parallel simulations of aerosol influence on clouds using cloud-resolving and single-column models, J. Geophys. Res., 110, D15S10, doi:10.1029/2004JD005088, 2005.

Pawlowska, H. and Brenguier, J.-L.: Microphysical properties of stratocumulus cloud during ACE-2, TELLUS, 52B, 868-887, 
2000.

Pawlowska, H. and Brenguier, J.-L.: An Observational study of drizzle formation in stratocumulus clouds for general circulation model (GCM) parameterizations, J. Geophys. Res., 108(D15), 8630, doi10.1029/2002JD002679, 2003.

Pawlowska, H., Grabowski, W. W., and Brenguier, J.-L.: Observations of the width of cloud droplet spectra in stratocumulus, Geophys. Res. Lett., 33, L19810, doi:10.1029/2006GL026841, 2006.

Penner, J. E., Dong, X., and Chen, Y.: Observational evidence of a change in radiative forcing due to the indirect aerosol effect, Nature, 427(15), 231-234, 2004.

Penner, J. E., Quaas, J., Storelvmo, T., Takemura, T., Boucher, O., Guo, H., et al.: Model intercomparison of indirect aerosol effects, Atmos. Chem. Phys., 6, 3391-3405, 2006, http://www.atmos-chem-phys.net/6/3391/2006/.

Putaud, J. P., Van Dingenen, R., Mangoni, M., Virkkula, A., Maring, H., Prospero, J. M., Swietlicki, E., et al.: Chemical mass closure and assessment of the origin of the submicron aerosol in the marine boundary layer and the free troposphere at Tenerife during ACE-2, TELLUS, 52B, 141-168, 2000.

Raes, F., Bates, T., Mcgovern, F., and Van-Liedekerke, M.: The second Aerosol Characterization Experiments (ACE-2) general overview and main results, TELLUS, 52B, 111-125, 2000.

Rogers, R. R. and Yau, M. K.: A short course in cloud physics, Butterworth-Heinemann Publication, Woburn, MA, 1989.

Schroder, M., Bennartz, R., Schuller, L., Preusker, R., Albert, P., and Fischer, J.: Generating cloud masks in spatial highresolution observations of clouds using texture and radiance information, Int. J. Remote Sens., 23, 4247-4261, 2002.

Snider, J. R. and Brenguier, J.-L.: Cloud condensation nuclei and cloud droplet measurements during ACE-2, TELLUS, 52B, 828842, 2000.

Snider, J. R., Guibert, S., Brenguier, J.-L., and Putaud, J.-P.: Aerosol activation in marine stratocumulus clouds: 2. Kohler and parcel theory closure studies, J. Geophys. Res., 108(D15), 8629, doi:10.1029/2002JD002692, 2003.
Stephens, G. L.: Radiative profiles in extended water clouds. II: parameterization schemes, J. Atmos. Sci., 35(11), 2123-2132, 1978.

Stephens, G. L.: Cloud feedbacks in the climate system: A critical review, J. Climate, 18, 237-273, 2005.

Stevens, B. Lenshow, D. H., Faloona, I., Moeng, C.-H., et al.: On entrainment rates in nocturnal marine stratocumulus, Quart. J. Roy. Meteorol. Soc., 129, 3469-3492, 2003a.

Stevens, B., Lenschow, D. H., Vali, G., Gerber, H., Bandy, A., Blomquist, B., Brenguier, J.-L., Bretherton, C. S., Burnet, F., Campos, T., Chai, S., Faloona, I., Friesen, D., et al.: Dynamics and chemistry of marine stratocumulus-DYCOMS-II, Bull. Amer. Meteorol. Soc., 84, 579-593, 2003b.

Twomey, S.: The influence of pollution on the shortwave albedo of clouds, J. Atmos. Sci., 34, 1149-1152, 1977.

Textor, C., Graf, H.-F., Herzog, M., and Oberhuber, J. M.: Injection of gases into the stratosphere by explosive volcanic eruptions, J. Geophys. Res., 108(D19), 4606, doi:1029/2002JD002987, 2003.

Verver, G., Raes, F., Vogelezang, D., and Johnson, D.: The 2nd aerosol characterization experiment (ACE-2) meteorological and chemical context, TELLUS, 52B, 126-140, 2000.

Xie, S., Xu, K. M., Cederwall, R. T., Bechtold, P., Del Genio, A. D., Klein, S. A., Cripe, D. G., Ghan, S. J., et al.: Intercomparison and evaluation of cumulus parameterizations under summertime midlatitude continental conditions, Quart. J. Roy. Meteorol. Soc., 128, 1095-1135, 2002.

Xie, S., Zhang, M., Branson, M., et al.: Simulations of midlatitude frontal clouds by single-column and cloud-resolving models during the Atmospheric Radiation Measurement March 2000 cloud intensive operational period, J. Geophys. Res., 110, D15S03, doi:10.1029/2004JD005119, 2005.

Xu, K.-M., Cederwall, R. T., Donner, L. J., Grabowski, W. W., et al.: An inter-comparison of cloud-resolving models with the Atmospheric Radiation Measurement summer 1997 IOP data, Quart. J. Roy. Meteorol. Soc., 128, 593-624, 2002.

Xue, H. W. and Feingold, G.: Large eddy simulations of trade wind cumuli: Investigation of aerosol indirect effects, J. Atmos. Sci., 63, 1605-1622, 2006. 